$$
212-23
$$

OANL-5116

\title{
Interface Stability During the Oxidation of Binary Alloys
}

Gregory J. Yurek

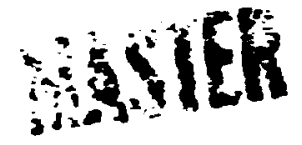

OAK RIDGE NATIONAL LABORATORY

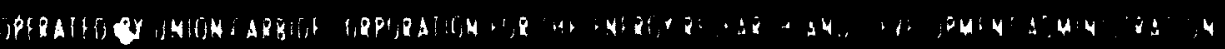




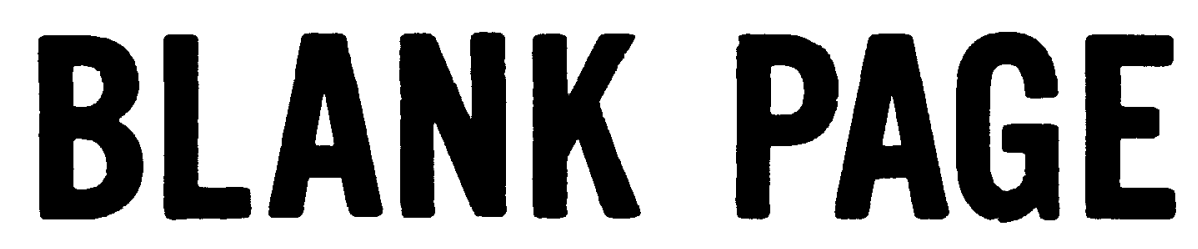

$r^{d}$ 


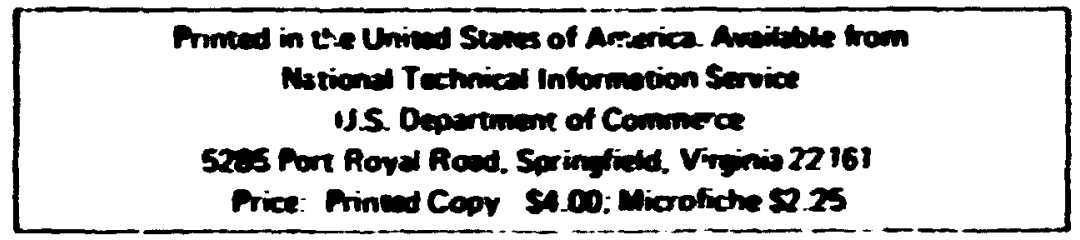

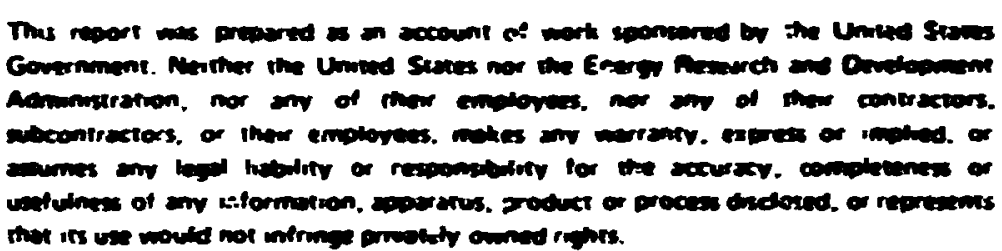


ORAL-5116

: 25 - interials

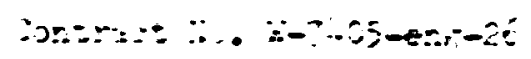

METLE AIT CERAMICE IT:ISIA:

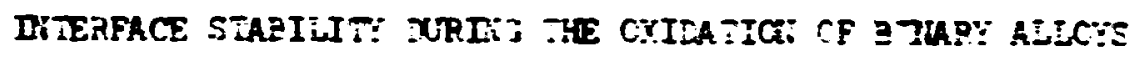

Fregory J. Yurek

APRIL 1976

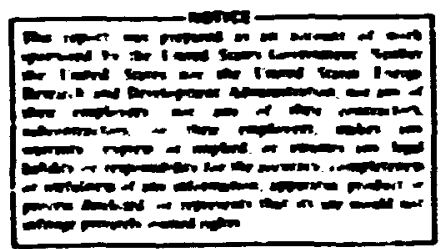

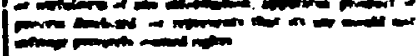

\author{
OAK RIDTE NATIOAL LABORATORY \\ Cak Ridge, Tennessee $37 \& 30$ \\ operated by \\ INION CARBIDE CORPORATION \\ for the \\ ENERTY RESEARCH ARD DEVELOPNENT ADMEISTTRATTON
}


¿2:-9:

ASTEKT - . - . . . . . . . . . . . . - . . . . . .

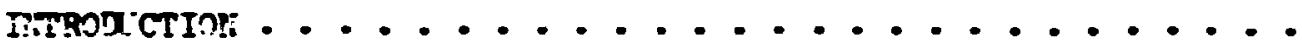

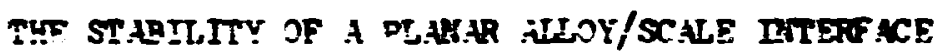

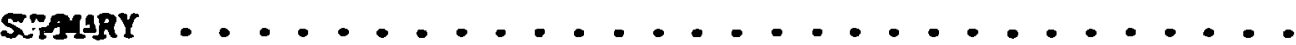

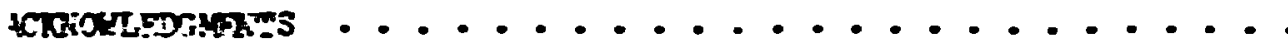

PSTEREACSS 
Sregory J. Yurek

Metals and Cerenics Division

Dek Ridge intiocal Leboratory

Oak Ridge, Tennessee $3793 \mathrm{C}$

\section{AESIRACT}

Ithe statility of a plear elloy/scale internce turing the diff:sion-controlled oxithtion of a bonoteneous, singlephase bizary alloy depends CI both the thernodyanic and trensport properties of the syste under consideration. A criturion is presented that can be eployed to predict the statility of piana alloy!scele interfece for the specified reection: tesperature, elloy conpsition. and chenical potentiel of the oxidert when only orse component of the alloy is oxidized, enion diffusion predoninotes in the scaie, and the solisiditity of orygen in the elloy is essentielly eero. A plame elloy/scele interfece (a single-phase scale) is the preferred grourth arphology if firfusion in tizm xide phase is the rate-liniting step of the orifintion reezion. in ineven allog/sule interrase (a turo-phase scale! is expected if jimusion in the elloy praze is the rate-deteraining step. This stability critericr is equivient to the criterion derived by liagser for the cese sf predominant cation difrusion in the scale. 


\section{TMERORUCIION}

The hiph-tespereture axidation of a "-base alloy can respit in th: formtion of a two-phase product leyer (aide + alloy) on the surface of the -liloy. ' For exalple, the bigh-teperature axidation of "-lat elloys nas resulted in the formtion of surface scales that corsist of tro zuizes." As shown in Fig. I, a two-phase zone exists edjecent to the elloy; it compises strirgers of uraniun dioxide and sb-rich alioy, the long axes of which sre aligned perpendicular to the surfece a: the alloy. The second zone is a conpet layer of oxide that exists between the gas phase and the two-phese zone. The second zane aight contein some axides of niobiun, wich could be sormed during the Initisl stege of axidation and by cuidetion of the tips of the Mb-rich stringers. The formtior of the two-phass scales can be ascribed to the prefurential ofiation of one component of the alloy inder contitions for which a plamar alloy/scale interface is not stable. The stability of alanar alloy/scale interface depends on both the thermodmanic and tranoport froperties of the syste under consideration.

The purpose of this paper is to present a criterion for the stability of a pinar alloy/scale interfuce that can be eployed to rationlize the formtion of tro-phase scales on I-base alloys. This puper cl sely follous an earlier amalysis of Wagner ${ }^{3}$ for the stability of alanar alioy/scale interface during the oxidntion of binnry alloys that contain - nuble netal: however, the present work differs ron Wagner's analysis because anions, instead of cations, are supposed to be the nore nobile jons in the growing scale. As one might expect intuitively, besed on Wagner's earlier work, ${ }^{3}$ the criterion that is developed in this paper is equivelent to the criterion for the case of predominant cation difrusion ir the oxide phase. However, the ethematical analysis for the case of predominant anion difrusion is not avilable in the literature, and thus, the details of such an amalysis ere presented in this paper. 

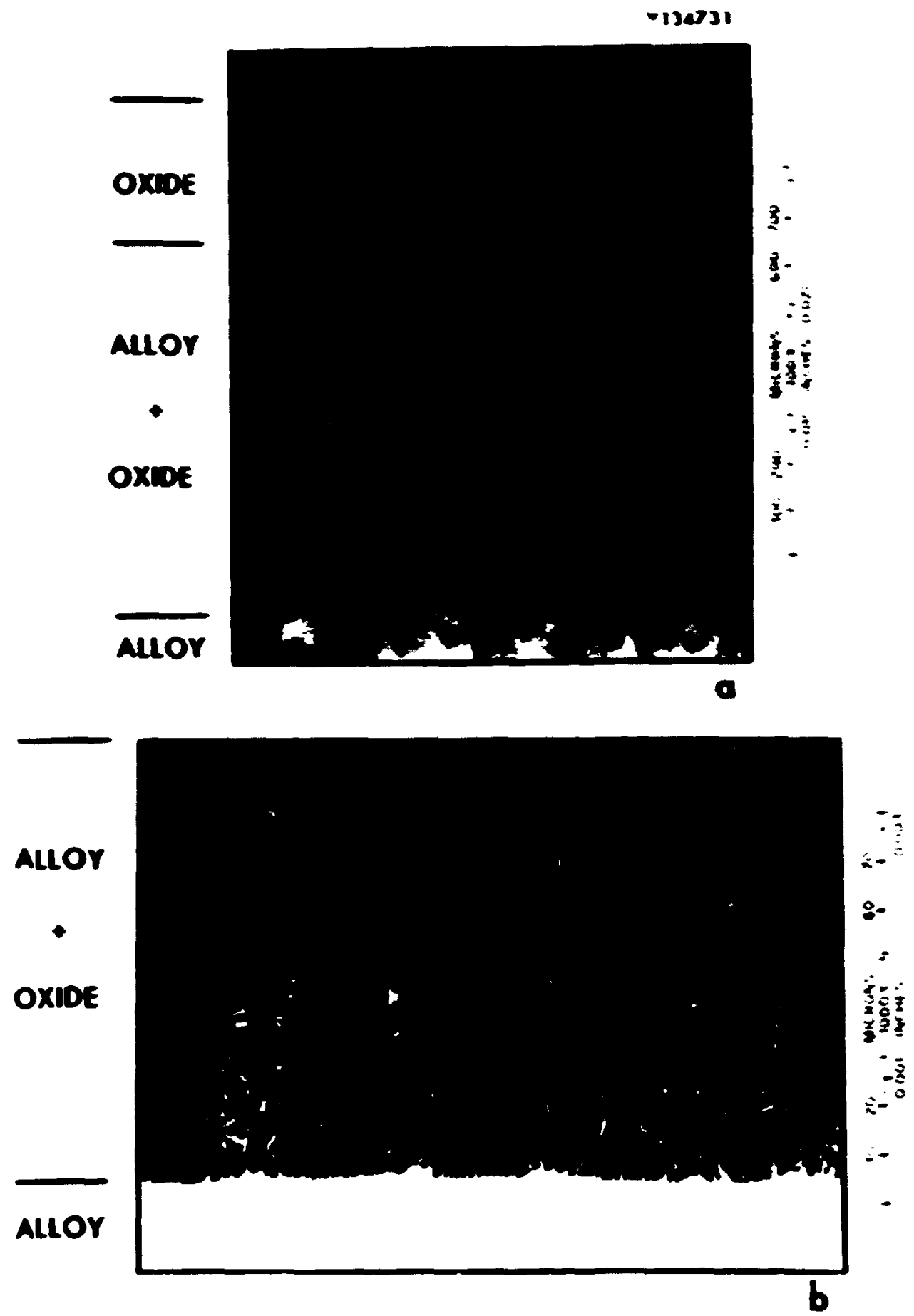

Fir. 1. Scales formed on a $\because-21 \mathrm{a} / 0 \mathrm{mb}$ allog: (a) 940 mit. $\quad C$ and 0.05 Torr oxysen, 100x; (b) 90 ait at 1100 ' $C$ and C.CS Torr oxygen, 1000x. After cethent, et $a 1.2$ 
THE STARILIT: OF A PLAKAR ALLOY/SCALE RTETFACE

A criterion is developed ir. this section to predict the stebility of a single-phese scale fo plame alioy!scale internce! suring the axitetion of en elioy inder liealized conditions. The purpose is to develop a wodel that can leonstrete the efrect of the systen verietles os interfece stability durine axidntisr, thereby leading to - ketter insterstaxting of the Eechanises of oxidntion for wore coplex ceses.

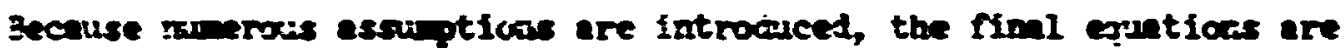
onli senf-risatitative.

The axiletion of an fiteal alloy sol sc listioc, $t-8$, in which copponent $E$ is a noble ental. Is considered. Conposent A is selectively milized to for the oxide $\omega_{v}$, a compound seficonductor thet ahitits

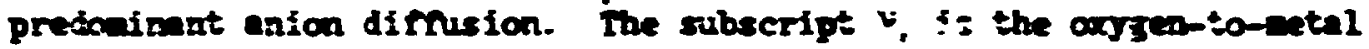
retis for the oxide in coexistence vith pure meal $A_{;}$a subseript is eployed for other oxstea-to-eetal retios. It is possible that conponent i can be selectively pxidized erea if component $a$ is not a sotle netal. In this case, the absolute vilie of the free energy of formtisa $\mathrm{A}_{\mathrm{y}}$. aut be ach lerger then the absoijte value of the ree energ of formtios of the larest aride of component B, $w_{v}$, ast gros mich faster then the arides of conponent a turing the initiel steges of axidation, and tine concentration of $a$ in the elloy ast be relatively lar.

In order to deternine the stability of a planar ailog/scele interface, the relative rates of wowent, of ifferent reglons of a sligbtly pertritzed alloy/scale interface are exenined. A sinewave pertirbetion of the alloy/scale interrece, es shown in Fig. 2, is eployed for this odel.' Difnusion in both the alloy and oxide phases must be considered. The nur of coponent $A$ in the alloy in the $x$-tirection is giten by

$$
\left.f^{\prime}{ }^{\prime} x\right)=-\Sigma \frac{3 c_{A}^{\prime}}{2 x}
$$

where $\widetilde{T}$ is the interdifrusion ccefficient for the alloy, $c_{A}^{\prime}$ is the concentration of $A$ in moles/cm, and $x$ is the distance rrom the original 


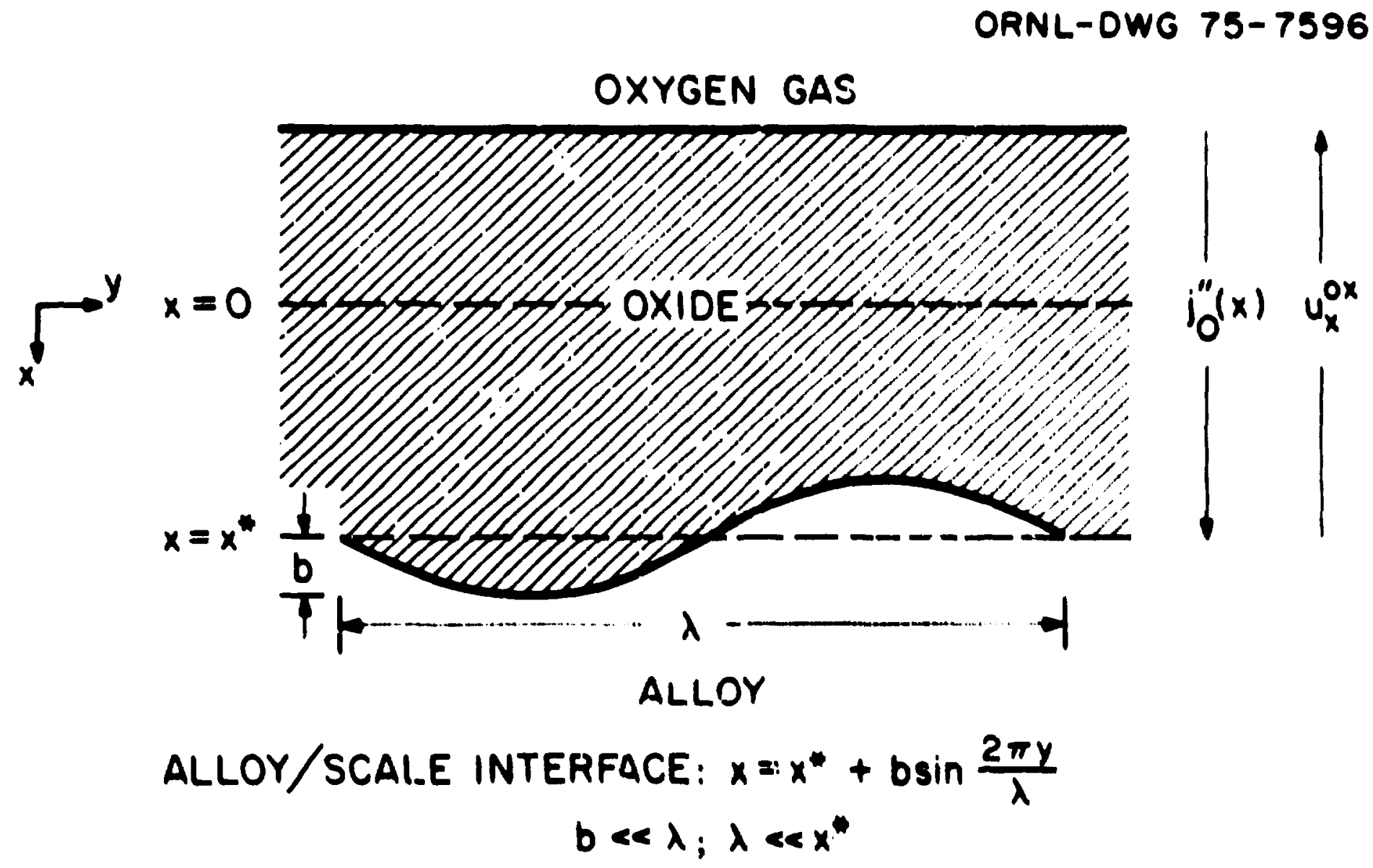

Fic. 2. Schematic representation or a crose nection throuph a inale-phase oxide acele on en assoy with an uneven alloy/acale interrace. 
sirfuce of the elloy. If the elloy is $\mathrm{xn}$ ideal solj: solitition. then

$$
a_{t}=x_{i}^{\prime}=a_{i}^{\prime} \mathbf{r}^{\prime}
$$

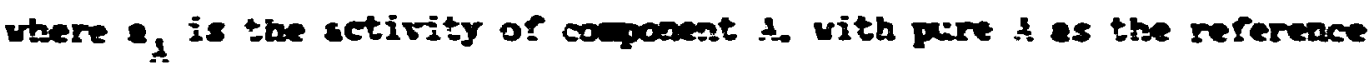
state. $\dddot{I}_{i}^{\prime}$ is the wole rection of $A$ in the alloy, and $v^{\prime}$ is the wolar voline of the alloy. which is essined to be in epeadent of coppsition.

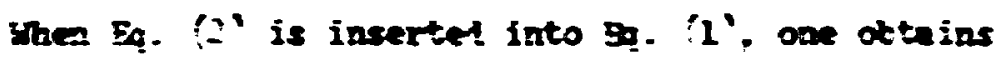

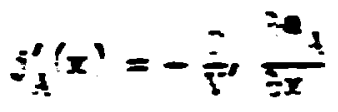

$\mathrm{mo}$

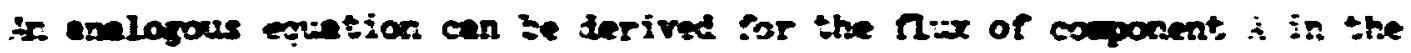
J-direction: therefore. when is is aved to te indegendert of coposition.. Fick's secoad ler cas be uritter as

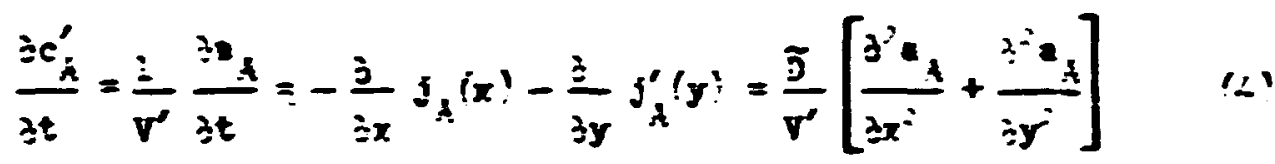

It is essuned that the dirrisivity of the enions is auch oreater than the difrusivity of the cations in the oxide. Thersfore, the fifrusion-controlled sxidation of the alloy requires tranorort of asgen enions through the sales rron the ssale/cas intertece to the alloy/scale interfece, where additionl suide is forned. If the oxide is a compound seniconhictor. then the flux of enione in the positive $x$-direction with respect to the origiml surfece of the allog $(x=)$ ) is given by

$$
j_{0}^{\prime \prime}(x)=-g_{0}^{2} c_{\partial}^{\prime \prime}\left(\frac{\partial / m_{0}}{\partial x}\right)+u_{x}^{\alpha x} c_{0}^{\prime \prime}
$$


where $t_{f}^{3}$ is the selt iimusion coeficient ior exious in the scale, $e^{\prime \prime}$ is the concentretion of arree in the scele in soles/ar", end is neesired with respect to $x=?$. is the reixcity of the oxide that is crised by the expension of the scale in the segetive $x$-direction.

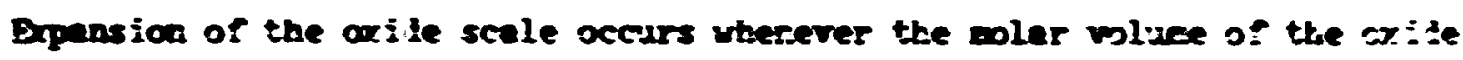
is oreater tian the piar woline of the netal ron whict it form.

The self dimusion coefricient for wrres is if is assinet to exhibit the rollarifg dependence $x$ the sctivity of xyrger:

$$
i_{n}^{s}=I_{j}
$$

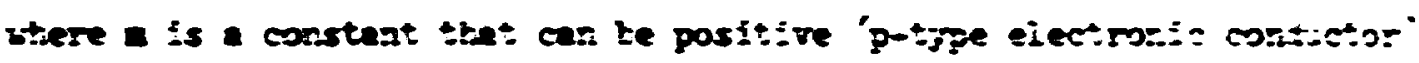

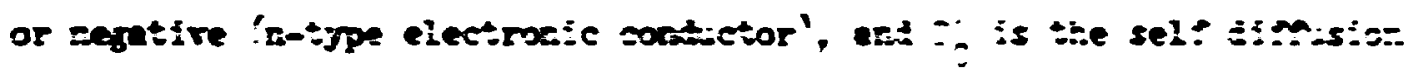

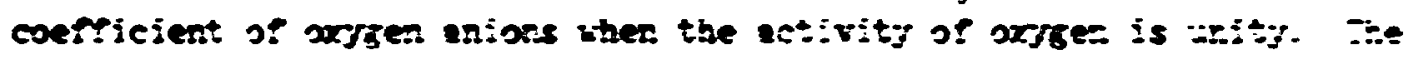

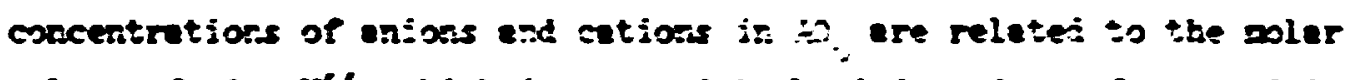

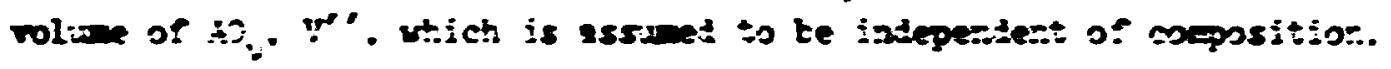
es follous:

$$
f_{\lambda}^{\prime \prime}=k_{i}^{\prime \prime}=\varepsilon_{2}^{\prime \prime}=\mu_{i}^{\prime \prime}
$$

Insertion of Fes. "

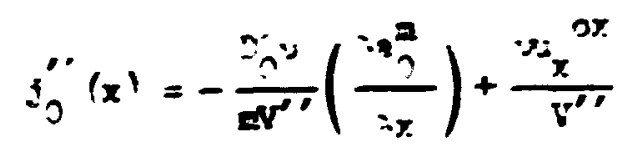

i stailar equetion cen be derfved for the nux of axyen enions in the y-direction.

If the oxite deform plastically and its woler volune remins constant (incompressible nuid' then the velocity cosponents that erise because of plastic deformtion ast have zero divergence." Thus,

$$
\frac{\partial}{\partial x} u_{x}^{o x}+\frac{j}{\partial y} u_{y}^{e x}=
$$


S.quation (9) is a relationship between the velocity components that arise from the plastic deformation of the oxide. Plastic deformation of the oxide is required because $\mathrm{v}^{\prime \prime} / \mathrm{v}^{\prime}>1$ and the local rate of oxide formation varies elong the irregular alloy/scale interface. The :elocity components in Eq. (9) are not necesserily equal to the velocity romponents for the movement of the elloy/scale interface, although the two velccities are relnted (see below). In the case of predominant cation diffusion in the scale, the velocity of the alloy/scale interface tourd the center of the allov (a Kirkendall efrect) is equal to the velucity of the scale owing to plastic deformation because continuous adhesion of the oxide to the alloy is assuaned. ${ }^{3}$

If quasi-steady-state growth of the cxide is assumed, then $3 c_{0}^{\prime \prime} / 3 t \equiv 0$, and it follows froe Eqs. (9) and (9) that

$$
\frac{\partial c_{j}^{\prime \prime}}{\partial t}=-\frac{\partial}{\partial x} f_{0}^{\prime \prime}(x)-\frac{\partial}{\partial y} f_{0}^{\prime \prime}(y)=\frac{D^{*} c^{v}}{m V^{\prime \prime}}\left(\frac{\partial^{2}{ }_{0}^{F}}{\partial x^{2}}+\frac{\partial^{2} a_{0}^{\prime \prime}}{\partial y^{2}}\right)=0
$$

The locus of the alioy/scale interface is given by

$$
x=x^{*}+b \sin \left(\frac{2 \pi y}{x}\right)
$$

where $x^{*}$ defines the position of an average interface, $b$ is the amplitude of the sine-wave frofile and $\lambda$ is the wavelength (see Fig. 2 ). It is assuned tnroughout that

$\boldsymbol{t} \ll \lambda$

and

$$
\lambda \ll x^{*}
$$


i.e., the perturbation is supposed to be very small relative to the thickness of the scale.

In order to determine the stability of a planar alloy/scale interface, an expression rust be derived far the drift reloelty of the perturbed alloy/scale interface as a runction of position along the interface. The drift velocity of the alloy/scale interface in the positive $x$-direction, measured with respest to the origianl surface of the alloy, is designated as $u_{x}$.

The concentration of oxygen at the alloy/scale interface changes liscontinuously from $c_{0}^{\prime \prime}$ to $c_{0^{\circ}}$ Application of the principle of the conservation of mass yields

$$
\begin{aligned}
& i_{0}^{\prime \prime}(x)-j_{0}^{\prime}(x)=u_{x}\left(c_{0}^{\prime \prime}-c_{0}^{\prime}\right) \\
& \text { sit } x=x^{x}+b \sin \left(\frac{2 \pi y}{y}\right)
\end{aligned}
$$

where $j_{0}^{\prime \prime}(x)$, which is given by Eq. (5), is the total flux of oxygen that arrives at the alloy/scale interface, and $j_{j}(x)$ is the flux of oxygen in the alloy in the fositive $x$-direction. If the solubility of axygen in the alloy is assumed to be virtually zero, then Eq. (13) becorses

$$
\begin{gathered}
j_{0}^{\prime}(x)=u_{x} c_{0}^{\prime \prime} \\
\text { at } x=x^{*}+b \sin (2 \pi y / x)
\end{gathered}
$$

Insertion of Eq. (13a) into Eq. (8) ylelds, with the aid of Eq. (7), 


$$
\begin{aligned}
u_{x}^{\partial x} & =u_{x}+\frac{D_{0}^{*}}{a}\left(\frac{\partial a_{0}^{m}}{\partial x}\right) \\
\text { at } x & =x^{*}+b \sin (2-y / 1) .
\end{aligned}
$$

Afplication of tine principle of the conservation of rass to the transfer of component A rrom the alloy to the oxide yields

$$
\begin{aligned}
& z_{A}^{\prime}(x)-j_{A}^{\prime \prime}(x)=u_{x}\left(c_{A}^{\prime}-c_{A}^{\prime}\right) \\
& \text { at } x=x^{*}+b \sin (2-y / y)
\end{aligned}
$$

Although the diffusional flux of cations in the scele is assured to be essentially zero, there does exist a flux of cations in the oxide with respect to $x=0$ because of the expansion of the sxide. Hence,

$$
j_{A}^{\prime \prime}(x)=u_{x}^{o x} c_{A}^{\prime \prime}
$$

Couponent $B$ is not oxidized; therefore, the flux of $B$ in the scale is zero. However, as component $A$ is selective'y oxidized, component B must diffuse in the alloy toward the center of the alloy. From the principle of the conservation of the mass it follows that

$$
\begin{gathered}
j_{B}^{\prime}(x)=u_{x} c_{B}^{\prime} \\
\text { at } x=x^{*}+2 \sin (2 \pi j / \lambda) .
\end{gathered}
$$


If the molar volue of the alloy is indeperdent of comosition, then

$$
i_{A}^{\prime}(x)=-j_{G}^{\prime}(x)
$$

Substitution of Eqs. (16), (17), and (18) into Eos. (14) and (15) yrelds

$$
u_{x}=-\frac{v^{\prime \prime}}{v^{\prime \prime}} \frac{D_{j}^{\prime \prime}}{i: x}
$$

$$
\text { et } x=y^{*}+b \sin (2-y / y)
$$

Upon insertion of Eq. (19) into Eq. (13) and the use of Eq. (8), one obtains

$$
\begin{aligned}
& u_{x}^{o x}=\left(1-v^{\prime} / v^{\prime}\right) \frac{D_{0}^{*}}{x}\left(\frac{\lambda a_{0}^{m}}{\lambda x}\right) \\
& \text { at } x=x^{*}+b \sin (2+y / \lambda) .
\end{aligned}
$$

Division of Eq. (19) by Eq. (20) yields

$$
u_{x}^{o x}=-\left[v^{\prime \prime} / v^{\prime}-1\right] u_{x}
$$

Note that $u_{x}=u_{x}^{o x}$ only if $v^{\prime \prime} / v^{\prime}=2$. The minus sion appears in Eq. (2Oa) because the alloy/scale interface moves in the positive $x$-direction and 
the axide expends in the neative $x$-direction. Equations (2Ca), which yields the retio of the thichresses of the oxide on either side of $x=0$, can also be derived by simply considering the volvene changes that occur when a civen anount of wetel is converted to oxide and irregularities at the allog/scale interface are salll.

Substituition of Eqs. (2), (3), (7), (16), and (20) in Eq. (15) yieids

$$
\begin{aligned}
& v_{x} \frac{a_{A}^{\prime}}{r^{\prime}}=-\frac{E_{0}^{\circ}}{V^{\prime \prime}}\left(\frac{\lambda z_{0}^{m}}{2 x}\right)_{\text {oxide }}-\frac{D}{V^{\prime}}\left(\frac{\lambda a_{A}}{2 x}\right)_{a l l o y} \\
& \text { at } x=x^{*}+0 \sin (-i y)
\end{aligned}
$$

Upon combination of Eqs. (2), (3), (17), and (18) one obtains

$$
\begin{aligned}
& u_{x}\left(1-a_{A}\right)=\sigma\left(\partial a_{A} / \partial x\right)_{a l l o y} \\
& \text { at } x=x^{*}+b \sin (2 \pi y / x)
\end{aligned}
$$

if Eqs. (21) and (2.2) or B̈gs. (21) and (19) are ambined and $u_{x}$ is eiminated, one obtains the following condition:

$$
\begin{gathered}
\frac{D}{V^{\prime}}\left(\frac{\partial a_{A}}{\partial x}\right)_{a_{l l o y}}=-\left(1-a_{A}\right) \frac{D_{0}^{0}}{V^{\prime \prime} m}\left(\frac{\partial a_{0}^{m}}{\partial x}\right)_{\text {oxide }} \\
\text { at } x=x^{*}+b \sin (2 \pi y / \lambda)
\end{gathered}
$$


In order to obtain an expression for the local iate of morement of the ellog/scale inierrece, difrerential equations (4) and (10) aust be solved in accordance with tix s=umier: condition expressed by Eq. (23). The solutions of difrerential equations $(4)$ ans $(10)$ cen be written as the sur of two terms:

$$
\begin{aligned}
& a_{A}-F^{\prime}(x, t)+r^{\prime}(x, y, t) \\
& \text { if } x>x^{*}+b \sin (z-J / \cdot)
\end{aligned}
$$

and

$$
\begin{aligned}
& a_{0}^{m}=F^{\prime \prime}(x, t)+f^{\prime \prime}(x, y, t) \\
& \text { if } x<y^{*}+b \sin (y / x)
\end{aligned}
$$

where $F^{\prime}(x, t)$ and $F^{\prime \prime}(x, t)$ represent knom solutions of Eqs. (4) and (10), respectively, for a planar alloy/scale interface. The terms $f^{\prime}(x, y, t)$ and $f^{\prime \prime}(x, y, t)$ are perturbation functions, which represent the disierence between the solutions for a sine-wave profile of the alloy/scale interface and a planar interface.

Wagner ${ }^{3}$ introduced approximations for the perturbation runctions that are independent of time:

$$
\begin{gathered}
f^{\prime}=v^{\prime} c^{\prime} b \exp \left[-\frac{\lambda\left(x-x^{*}\right)}{\lambda}\right] \sin \left(\frac{2 \pi y}{\lambda}\right) \\
\text { if } x>x^{*}+\sin (2 \pi y / \lambda)
\end{gathered}
$$


and

$$
\begin{aligned}
r^{\prime}= & v^{\prime \prime} c^{\prime \prime} b \exp \left[\frac{2 r\left(x-x^{*}\right)}{\lambda}\right] \sin \left(\frac{-T y}{\lambda}\right) \\
& \text { if } x<x^{*}+b \sin (2 y / x)
\end{aligned}
$$

where the products $b c^{\circ}\left(=b \frac{3 F^{\prime}}{3 x}\right)$ and $b c^{\prime \prime}\left(=b \frac{\partial F^{\prime \prime}}{3 x}\right)$ give the anplitudes of the activity perturbetions far $x=x^{*}$ at the corresponding tive $t$, and $v^{\circ}$ and $y^{\prime \prime}$ are proportionality constants. At larje distances from the average interface $\left(x \gg x^{*}\right)$, the perturbation functions are essentialy equal to zero, and the solutions of Eqs. (4) and (10) are given by the planar interface solutions. This must be the case because the perturbaticas at the interface are assumed to be very swall. ht the everage interface $\left(x=x^{*}\right)$, the perturbation runctions assture the fort of a sine wave.

although the perturbation functions cannot be independent of time, It is assued that they are essentially stationary with respect to the average interface and that their magnitudes change only slowly. Hagner" showed that the use of the time-independent forms of the perturbation runctions, Egs. (25) and (26), are reasonable approximations for $f^{\prime}(x, y, t)$ and $\rho^{\prime \prime}(x, y, t)$ if

$$
u_{x} \ll \frac{2 \pi D}{x}
$$

or

$$
\lambda \ll \frac{2 \pi D}{u_{x}}
$$


Thus, the use of Eqs. (25) and (26) as apsorientions for the perturbetion runctions in the rurther developaent of a criterion for the stability of a planer allog/scale interfsce requires that the wave length of the sine-wive profile be surficiently smill to satisfy Eq. (2R).

at large distances row the average allcy/scale interface, the jerturbetion ractions are zero, and the solutions of Eqs. (4) and (10) are given by the solutions five a planar interface. As an aFroxiration far the planar interface solutions, $F^{\prime \prime}(x, t)$ ani $F^{\prime \prime}(x, t)$, the first two terns of a Tajlor's Series for the $F(x, t)$ atout the point $x=x^{*}$ at $t=t^{*}$ are enloyed. Thu, with the aid of Eqs. (25) and (2t;, Ferticilar solutions for differential Egs. (4) and (10) at $t=t "$ can be written as:

$$
\begin{aligned}
& a_{A}=a_{A}^{*}+c^{\prime}\left\{\left(x-x^{*}\right)+v^{\prime} b \exp \left[\frac{-2-\left(x-x^{*}\right)}{\lambda}\right] \sin \left(\frac{2 \pi}{\lambda}\right)\right\} \\
& \text { for } x>x^{*}+b \sin (-y / x)
\end{aligned}
$$

and

$$
\begin{gathered}
a_{0}^{m} \equiv\left(a_{0}^{*}\right)^{m}+c^{\prime \prime}\left\{\left(x-x^{*}\right)-v^{\prime \prime} t \exp \left[\frac{2 \pi\left(x-x^{*}\right)}{\lambda}\right] \sin \left(\frac{2 \pi y}{\lambda}\right)\right\} \\
\text { for } x<x^{*}+b \sin (2 \pi / \lambda)
\end{gathered}
$$

where $a_{A}^{*}$ and $a_{0}^{*}$ are the activities of $A$ and $O$ at the average interface plane $\left(x=x^{*}\right)$. 
In order to celculate the ectivities of $A$ and a st the alloy/seale interface, Juslor's Series expansi tas are ised for the exposential ruetions in Eqs. (29) and (30) and Eq. (12) is eployed to jield:

$$
a_{i}^{i}=z_{i}^{*}+c^{\prime}\left(1+v^{\prime} ! b \sin \left(\frac{j}{i}\right)\right.
$$

end

$$
\left.\left[\begin{array}{l}
1 \\
0
\end{array}\right]^{2}=[0]\right]^{n}+c^{\prime \prime}\left(1-v^{\prime \prime}\right) b \sin \left(\frac{2 \pi}{x}\right)
$$

where $a_{A}^{i}$ and $a_{0}^{i}$ are the activities of $A$ and $O$ at the locus of the alloy! scale interface, which is given by Eq. (11). Feras involving powers of b that are greater than or equal to two ere disregarded, because, according to Eq. (12), the magnitude or $b$ is very $s$ mall.

Because only small deviations from a planar interface are considered, $\Omega_{0}^{i} \sim \Omega_{0}^{*}$. Zzon rearrangement of Eq. (32) one obtains

$$
\frac{a_{0}^{1}}{a_{0}^{n}}=\left[1+\frac{c^{\prime \prime}\left(1-v^{\prime \prime}\right)}{\left[a_{0}^{m}\right]^{m}} b \sin \left(\frac{2 y y}{\lambda}\right]^{1 / m}\right.
$$

If $a_{0}^{\frac{1}{1}} / a_{0}^{*} \sim 1$, the first two terms of a series expansion can be used as an approximation for the right-hand-side of Eo. (33) to yield

$$
a_{0}^{1}=a_{0}^{*}\left[1+\frac{c^{\prime \prime}\left(1-\gamma^{\prime \prime}\right)}{m\left[a_{0}^{w}\right]^{m}} b \sin \left(\frac{2 \pi y}{\lambda}\right)\right]
$$

when power $0: b$ greater than unity are disregarded. 
Equations (29-?1) can be substituted in the bouning equtios, 5q. (23). Then, wen Julor's series expensions are explased for the exponeatial ructions and powers of b ereater than units are dismeonded, one obtains

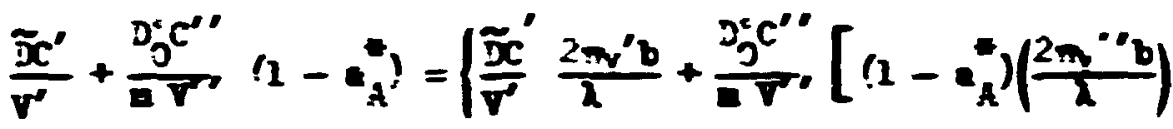

$$
\begin{aligned}
& \left.\left.+\left(1+v^{\prime}\right) b c^{0}\right]\right\} \sin \left(\frac{-\frac{x}{x}}{x}\right)
\end{aligned}
$$

Equation (35) is of the fore $(A+E)=(C+D) f(y)$, where $h, E, C$, and $J$ are constants and $y$ is a variable. Mis equation can be satisfied only if $(A+B)=0$ and $(C+D)=0$. merefore,

$$
\frac{D \tilde{E}^{\prime}}{\vec{v}^{\prime}}=-\frac{D_{0}^{c} C^{\prime \prime}}{\bar{R}^{\prime \prime}}\left(:-a_{A}^{*}\right)
$$

and

$$
\frac{\tilde{D} C^{\prime} 2 \pi v^{\prime} b}{\lambda v^{\prime}}=-\frac{D_{0}^{\circ} C^{\prime \prime}}{\nabla^{\prime}}\left[\left(1-a_{A}^{*}\right) \frac{2 \pi v^{\prime \prime} b}{\lambda}+\left(1+v^{\prime}\right) b C^{\prime}\right]
$$

Because 1. must be sufficiently small to satisfy Eq. (28), the first term in the brackets on the right-hand-side of Eq. (37) is wuch larger than the second term. Hence,

$$
\frac{\widetilde{C^{\prime} v^{\prime}}}{v^{\prime}}=-\frac{D_{0}^{c} C^{\prime \prime}}{m v^{\prime \prime}}\left(1-a_{A}^{*}\right) v^{\prime \prime}
$$




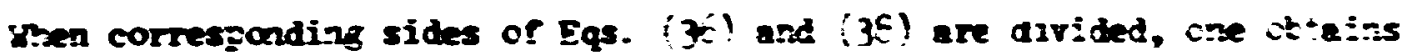

$$
v^{\prime}=v^{\prime \prime} \quad 191
$$

If local thersodmanic equilibrize is aintained at the allo/scale interface, then it follows tha:

$$
a_{A}^{i}(\mathbf{a l l o g})=a_{A}^{i}(\cos i d e)
$$

and

$$
a_{0}^{i}(\mathbf{a l l o y})=a_{0}^{i}(\text { oxide })
$$

At each point in the oxide scale, the activities of metal and oxyzen are related by $a_{A} a_{0} \because=r$, where $r$ is a constant at constant tewperature and total hydrostatic pressure if the chemical potential of the compound is independent of the composition of the oxide over the composition range of interest. Therefore,

$$
a_{A}^{*}\left(a_{0}^{*}\right)^{v_{c}}=r
$$

and

$$
a_{A}^{1}\left(a_{0}^{1}\right)^{\nu}=r
$$

Equations (40-43) are strictly valid only in the case of a planar alloy/ scale interface. If the alloy/scale interface is uneven, then the 


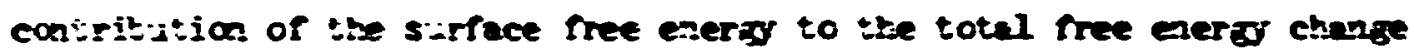
stoild be inclided. ijareref, beceuse of the lerge roline free energy

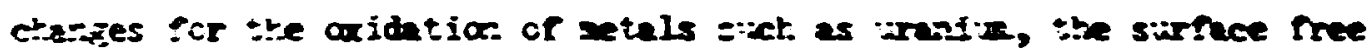
enera: efies: can be ignored except for rery sall ralizes of i, or, In vier ef Eq. (12), except for rery thin scales. In like Eaner, the effect of stresses on the free energy change is also ibored. Stress efrects sict as stress-essisted diffusios and cracking of the seale are assined not to be fresent. Coutintias of Iqs. (42) and (43) yields

$$
\frac{a_{0}^{i}}{a_{0}^{n}}=\left(\frac{a^{m}}{a^{2}}\right)^{-h_{1}}
$$

then Eq. (44) is cocpered with Eq. (33), one finds

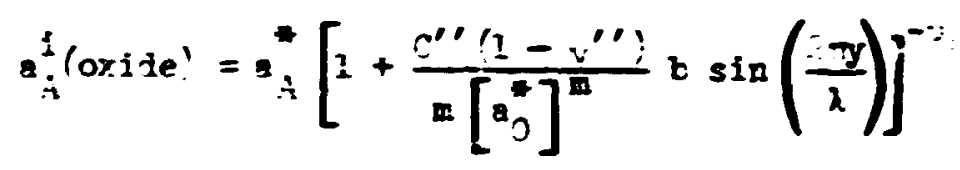

Insertion of Eqs. (31) ard (45) into Eq. (40) yields

$$
\frac{v c^{\prime \prime}\left(1-v^{\prime \prime}\right)}{m\left(a_{0}^{*}\right)^{m}}=-\frac{c^{\prime}\left(1+v^{\prime}\right)}{a_{A}^{*}}
$$

when Eq. (39) is used in Eq. (46), one can solve for $v^{\prime}$ and $\% "$ :

$$
v^{\prime}=v^{\prime \prime}=\frac{(q+1)}{(q-1)}
$$


usere

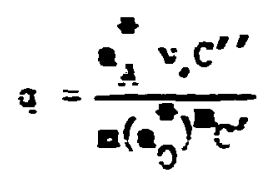

The retio $:^{\prime \prime} / c^{\prime}$ can be obtained roc sq. ( 36$)$; substitution in Eq. (4E) yields

$$
a=-v_{c} \frac{u_{A}^{\prime *}}{\left(1-n_{A}^{\prime *}\right)} \frac{\tilde{D}}{\left(n_{0}^{3}\right)^{*}} \frac{v^{\prime \prime}}{v^{\prime \prime}}
$$

were $\left(a_{0}^{3}\right)^{*}$ is the self-diffusion coefficient for orjgen anions at $x=x^{*}\left(a_{0}=a_{0}^{*}\right)$ and $I_{A}^{*}\left(=a_{A}^{*}\right)$ is the role fraction of couponent $A$ at $x=x$.

The local rate of movement of the alloy/scale interface toward the center of the alloy is given by Eq. (22). Substitution of Eqs. (29) and (31) in Eq. (22), and eveluation at $x=x^{*}$ yields

$$
u_{x}^{*}=\frac{\widetilde{D} c^{\prime}}{1-a_{A}^{*}}
$$

where $u_{x}^{*}$ is the veloct ty of the average alloy/scale interface. Insertion of Eqs. (29) and (31) Into Eq. (22) yields, when Taylor's Series expansions are used for the exponential functions and powers of $b$ greater than unity are 1 gnored,

$$
u_{x}-u_{x}^{*}=\left[u_{x} \frac{c^{\prime}\left(1+v^{\prime}\right)}{\left(1-a_{A}^{\prime}\right)}-u_{x}^{*} \frac{2 n^{\prime \prime}}{\lambda}\right] b \sin \frac{2 \pi y}{\lambda}
$$


if $\vdots$ is reg seell, then the second ters in brackets in Eq. (5,1) is zidet larber then the firs: terz Therefore,

$$
u_{x}-u_{x}=-u_{x} \frac{a v}{x} \sin \left(\frac{-y}{x}\right) \quad(x)
$$

Eqiations (4?) and (49) are sinilar, and Eq- (52) is ideatical, to the corresponding equations that iazmer derived for the case of predocinan: cation difrusion in the oxide. The same type of analysis for the statility of a planar alloy/scale interface is aprlicatle here.

In regions of the scale whe the lcal thichness exceeds the average thiciciess ( $\sin \frac{2^{3} y}{i}>0$ ), the sijn of $\%$ (or $\cdots$ ) determines whether the local interface velocity is greeter or less than she average interface velocity. If $y^{\prime}>0$, then $u_{x}\left\langle v_{x}^{*}\right.$, and the perturbations at the allog/scale interface stould decrease as the reaction proceeds; a nat interfece (a single-phase scale) is stable. 0 the other rand, if $y^{\prime}<0$, then $\lambda_{x}>{ }_{x}^{*}$ and the arflitide of the pertiurtations at the allcy/scale iriterface should increase as the reaction proceeds; that is, a flat interface is unstable with respect to a serrated or vary interface. A two-phase scale, wich comprises E-rich alloj and $\mathrm{AO}_{v}$, is expected to form on the alloy.

The sign of $y^{\prime}$ depends on the value of $q$, which is defined by Eq. (49). All of the constants in Eq. (49) are positive quantities, and $\mathrm{N}_{A}^{* *}$ is always less than infty. Therefore, $q$ is always a negative quantity. Hence, $\because>0$, and a flat interface is atable, when $|q|>1$; $y^{\prime}<0$, and a nat interface is not stable when $|q|<1$.

The application of the criterion for the stability of a planar alloy/ scale interface requires that values of $N_{A}^{*}$ and $\left(D_{0}^{s}\right)^{*}$ be known so that $q$ can be calculated. Values of $\mathrm{N}_{A}^{*}$ and $\left(D_{0}^{3}\right)^{*}$ can be obtained from equations derived by Wagner" for the oxidation of a binary alloy with a flat alloy/ scale interface. Wagner's model allow one to calculate a parameter, $\alpha$, 
which is equal to the parabolic rate constant for the oxidation of the alloy divided by the parabolic rate constant for the oxidaticn of the pure metal, A, as a runction of alloy composition at a given tempereture and orygen potential. When $a$ is equal to unity, then the rate-limiting step of the oxidation reaction must be difrusion in the oxide phase; that is, the alloy oxidizes at the same rate as the pure metai, and th'2s, difrision processes in the alloy have essentially no effect on the rate of axidation. Conversely, if $\alpha$ is less than unity, then the rate of oxidation of the alloy must be lifited by diffusion in the alloy phase.

If the rate of oxidation of the alloy were limited by difrusion in the oxide $(\alpha=1)$, then $\left(D_{0}^{s}\right)^{*} \ll D$ and $N_{A}^{\prime *}$ should not differ greatly from the bulk alloy composition (the oxygen potential at the alloy/scale interface should be virtually eqial to $\pi_{0_{z}}$, the oxygen potential fcr coexistence of pure $A$ and $\left.A_{V_{0}}\right)$. Furthermore, $v^{\prime \prime}>v^{\circ}$ and $v_{0} \geq 1$. Therefore, according to Eq. (49), the absolute value of $q$ is greater than unity; that is, a planar alloy/scale interiace is stable when the rate-limiting step o: the growth of the single-phase scale shown in Fig. 2 is diffusion in the oxide phase.

If the rate of oxidation of the alloy were linited by diffusion in the alloy phase $(\alpha<1)$, then $\mathbb{D} \ll\left(D_{0}^{s}\right)^{*}$ and $N_{A}^{* *} \ll 1$ (the oxygen potential at the alloy/scale interface should not differ greatly from the ambient oxygen potential). Therefore, according to Eq. (49), the absolute value of $q$ is less tian unity. A serrated alloy/scale interface (a two-phase scale) is the stable grouth morphoiogy when the rateliming step of the growth of the single-phase scale show in Fig. 2 is diffusion in the alloy phase. During steady-stace growth of the two-phase scale the cxygen potential at the growth front of the oxide should be virtually equal to $\pi_{B_{B}} / N_{A}^{b}$, where $N_{A}^{b}$ is the mole frection of component $A$ in the bulk elloy. At the prowth front, atons of component $B$ are supposed to move only short distances in the $y$-direction in order 
to allow fenetration of oxide into the elloy. The rate of penetration of oxide into the alloy should be approximately equal to the rate of thickening of the axide on pure metal $A$, as $20 n g$ as $k_{A}^{b}$ does not differ greatly from unity. ${ }^{3}$ This assumes that effects of grouth stresses or th: rate of oxidation are negligible.

Whener ${ }^{3}$ pointed out that a value of $|q|$ greater than inity is a necessary but not surficient condition for the stability of a planar alloy/scale interface. Other factors, such as interfacial tension, stresses in the scale and in the alloy, fast trensport along interfaces, and the grain size of the alloy could arfect the morpholozy of the scale. For example, interface tension would counteract the tendency to form an unever interface, while differerces in molar volunes of the alloy and the scale would fivor an unever. interface if this morcholoby minimized the overall stress in the syster.

The criterion for the stability of a planar interface has been applied to the oxidation of U-No alloys at elevated temperatures. The results of these experiments, which are in qualitative agreement with the criterion, will be presented in a ruture publication. 


\section{SURARY}

Analytical expressions have been derived to predict the stability of a flanar allo/scale interface during the aridation of binary alloys when anion diffusion predominates in the oxide scale. Only one conponent of the alloy is suppesed to be oxidized, and the solubility of oxyren in the alloy is supposed to be zero. According to the stability criterion, planar alloy/scale interface (a single-phase scale) is the preferred grouth morphology if diffusion in the oxide phase is the rate-limiting step of the oxidntion reaction. $R$ serrated alloy/ scale interface (a two-phase scale) is expected to develop during cxidation if difrusion in the alloy phase is the rate-determining step of the oxidation reaction.

This stability criterion is equivalent to the criterion derived by wagner ${ }^{3}$ for the case of predominant cation diffusion in the scale. The criterion can be applied to the axijation (sulfiation, etc.) of any binary alloy as $20 n g$ as the assumptions that were employed in the model are valid for the system under consideration. 


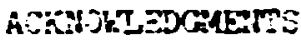

Dite author wishes to express his eppreciation to Jr. $I$. V. Cathcart for mary helpful discussions juring the witing of this peper, and to Drs. R. E. Pavel and R. A. Perkins for their critical readine of the manuscript. The author also wishes to express his fratitute te. \&5. C. Carter for her skiliful preparation of the anduscript. 


\section{REFEREATCES}

1. J. V. Cathcart, Proceedinzs, The Physical Hetallurgy of Uranium Allovs Conference, Vail, Colorado, Peb. 12-14, 1974, in press.

2. J. V. Cathcart, R. E. Pavel, and G. F. Petersen, Oxidation of Metals, 3. 497 (1971).

3. C. Hagmer, J. Electrochem. Soc., i03, 571 (1956).

4. C. Hazner, in "Aton Move-aits", ASM, Cleveland, P. 153, 1951.

5. F. B. Hildebrand, "Advanced Calculus for Applications", Prentice Hall, Englewood Clifrs, I. J., p. 290, 1362.

6. C. Hagner, J. Electrochem Soc., 99, 369 (1952). 